\title{
A Patient Dose-Reduction Technique for Neuroendovascular Image-Guided Interventions: Image-Quality Comparison Study
}

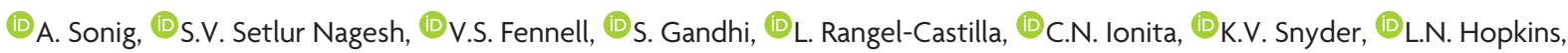 \\ (1)D.R. Bednarek, (1)S. Rudin, (1)A.H. Siddiqui, and DE.I. Levy
} O- $\square$

\begin{abstract}
BACKGROUND AND PURPOSE: The ROI-dose-reduced intervention technique represents an extension of ROI fluoroscopy combining $x$-ray entrance skin dose reduction with spatially different recursive temporal filtering to reduce excessive image noise in the dosereduced periphery in real-time. The aim of our study was to compare the image quality of simulated neurointerventions with regular and reduced radiation doses using a standard flat panel detector system.
\end{abstract}

MATERIALS AND METHODS: Ten 3D-printed intracranial aneurysm models were generated on the basis of a single patient vasculature derived from intracranial DSA and CTA. The incident dose to each model was reduced using a 0.7-mm-thick copper attenuator with a circular ROI hole (10-mm diameter) in the middle mounted inside the Infinix C-arm. Each model was treated twice with a primary coiling intervention using ROI-dose-reduced intervention and regular-dose intervention protocols. Eighty images acquired at various intervention stages were shown twice to 2 neurointerventionalists who independently scored imaging qualities (visibility of aneurysm-parent vessel morphology, associated vessels, and/or devices used). Dose-reduction measurements were performed using an ionization chamber.

RESULTS: A total integral dose reduction of $62 \%$ per frame was achieved. The mean scores for regular-dose intervention and ROI dose-reduced intervention images did not differ significantly, suggesting similar image quality. Overall intrarater agreement for all scored criteria was substantial (Kendall $\tau=0.62887 ; P<.001)$. Overall interrater agreement for all criteria was fair $(\kappa=0.2816 ; 95 \% \mathrm{Cl}$, $0.2060-0.3571)$.

CONCLUSIONS: Substantial dose reduction (62\%) with a live peripheral image was achieved without compromising feature visibility during neuroendovascular interventions.

ABBREVIATIONS: DRI = dose-reduced intervention; RDI = regular-dose intervention

X -ray dose reduction during interventional radiology procedures is of paramount importance. The concept of $\mathrm{x}$-ray dose reduction using ROI fluoroscopy has been previously introduced (On-line Fig 1). ${ }^{1-3}$ An extension of this concept is a technique that combines dose reduction with spatially different recursive tempo-

Received September 14, 2017; accepted after revision December 6.

From the Departments of Neurosurgery (A.S., V.S.F., L.R.-C., C.N.I., K.V.S., L.N.H., D.R.B., S.R., A.H.S., E.I.L.), Radiology (K.V.S., L.N.H., D.R.B., S.R., A.H.S., E.I.L.), and Neurology (S.G., K.V.S.), Jacobs School of Medicine and Biomedical Sciences, University at Buffalo, State University of New York, Buffalo, New York; Department of Neurosurgery (A.S., V.S.F., S.G., L.R.-C., K.V.S., L.N.H., S.R., A.H.S., E.I.L.), Gates Vascular Institute at Kaleida Health, Buffalo, New York; Toshiba Stroke and Vascular Research Center (S.V.S.N., C.N.I., L.N.H., D.R.B., S.R., A.H.S., E.I.L.), Department of Biomedical Engineering (C.N.I., S.R.), Department of Mechanical and Aerospace Engineering (S.R.), and Department of Electrical Engineering (S.R.), University at Buffalo, State University of New York, Buffalo, New York; Buffalo Neuroimaging Analysis Center (S.G.), Buffalo, New York; and Jacobs Institute (L.N.H., A.H.S.), Buffalo, New York.

Ashish Sonig and Swetadri Vasan Setlur Nagesh are co-first authors.

Paper previously presented as an oral presentation at: Annual Meeting of the Congress of Neurological Surgeons Meeting, September 26-30, 2015; New Orleans, Louisiana. ral filtering to reduce excessive noise in the peripheral dose-reduced region (ie, the region outside the ROI but within the FOV) and thereby restore image quality for improved visualization during an intervention. ${ }^{4-6}$ Spatially different temporal filtering is a mathematic filter that reduces noise in the fluoroscopic image. Our research team has constructed $3 \mathrm{D}$ printed models $\mathrm{s}^{7,8}$ that simulate patient-specific cerebrovascular anatomy and have been used to assess neuroendovascular techniques for stroke intervention, aneurysm coiling, and parametric imaging. ${ }^{8-12}$

In this study, we applied extended ROI fluoroscopy with enhanced visualization of the peripheral field during a simulated neuroendovascular intervention using patient-specific $3 \mathrm{D}$ printed

This work was supported, in part, by National Institutes of Health grant R01EB002873 and an equipment grant from Toshiba Medical Systems Corporation. Please address correspondence to Elad I. Levy, MD, MBA, University at Buffalo Neurosurgery, 100 High St, Suite B4, Buffalo, NY 14203; e-mail: elevy@ubns.com - Indicates open access to non-subscribers at www.ajnr.org

Indicates article with supplemental on-line photos.

http://dx.doi.org/10.3174/ajnr.A5552 
phantoms. The aim of our study was to compare the image quality of simulated neurointervention with regular and reduced radiation doses using a standard flat panel detector system.

\section{MATERIALS AND METHODS Dose Reduction}

An X-ray beam modulated by a differential attenuator reduces the actual dose of radiation received by a patient. A 0.7-mm uniform thick copper plate ${ }^{13}$ (offering 75\%-80\% attenuation for peak kilovoltage, ranging from 70 to $80 \mathrm{kV}$ [peak]) with a central circular void of $10 \mathrm{~mm}$ in diameter was used as an attenuator. ${ }^{14}$ This attenuator was mounted in place of an existing compensation filter inside the x-ray tube assembly of the Infinix C-arm (manufactured in 2012; Toshiba America Medical Systems, Tustin, California) and was moveable within the FOV. The mobility ensured that the circular opening could be placed over the treatment area (ie, the ROI). The ROI, which comprised $18 \%$ of the total FOV ( 8 inches $\times 8$ inches in the flat panel detector), received the regular dose. The area outside the ROI (periphery) received a lower dose, thus reducing the overall dose per frame.

The regular-dose intervention (RDI) simulations were performed using the technique parameters (kilovolt[peak], milliampere, and millisecond) calculated by the automatic exposure control of the $\mathrm{x}$-ray unit. To maintain the entrance air kerma within the ROI, we manually set the exposure parameters to the same values as the RDI parameters. The ROI attenuator was moved into the FOV, with the ROI aligned over the aneurysm; then, the ROIdose-reduced intervention (DRI) simulations were performed. The average exposure parameters for all the interventions were $70 \pm 2 \mathrm{kVp}, 50 \pm 10 \mathrm{~mA}$, and $10 \pm 2 \mathrm{~ms}$.

The ratio of the kerma-area product with and without the dose-reduction technique was used to assess the total amount of dose reduction achieved per image. The ratio is defined as

$$
\frac{K A P_{\text {dose reduced }}}{K A P_{\text {regular }}}=\frac{K A P_{\text {Periphery }} \times(F O V-R O I)+K_{\mathrm{ROI}} \times R O I}{K_{\mathrm{ROI}} \times F O V},
$$

where $K_{\mathrm{ROI}}$ is the entrance air kerma measured within the ROI and $K_{\text {Periphery }}$ is the entrance air kerma measured in the periphery. The air kerma was measured separately for the average exposure parameters using a 6-CC ionization chamber (TN34069; PTW Freiburg, Freiburg, Germany). The ionization chamber was placed beneath the patient table for detection of radiation in the ROI and the periphery. The measurements were repeated, and the averaged measurements were used for calculations.

\section{Image Enhancement}

Dose reduction using an attenuator results in an image with less brightness in the periphery (ie, those regions in which the radiation dose has been reduced). For improved visualization, the initial step is to equalize the brightness of the ROI and periphery. One approach is to subtract a mask image of the ROI attenuator; this step equalizes the brightness. ${ }^{2,3}$ In this study, all interventions were performed using the roadmap imaging technique. While using the ROI attenuator during roadmap generation, we registered the current position of the attenuator in the bone mask, which was then subtracted from the subsequent fluoroscopic images; this subtraction equalized brightness in the image. The pe- riphery has excess noise due to a lower dose reaching the detector. To decrease this noise and improve the signal-to-noise ratio, we used a novel spatially different recursive temporal filtering technique.

The following equation ${ }^{15}$ was used for the recursive temporal filtering technique:

$$
\begin{aligned}
I_{\text {current_output }}(x, y)=L_{\text {input }}(x, y) \times(1 & -\alpha) \\
& +I_{\text {previous output }}(x, y) \times \alpha,
\end{aligned}
$$

where $\alpha$ is the filter weight, ranging from 0 to $1 ;(x, y)$ is the spatial position of the pixel in the image; $I_{\text {input }}$ is the current image; $I_{\text {previous output is the previous noise-reduced image; and }}$ $I_{\text {current_output }}$ is the current noise-reduced image.

For the image pixels in the periphery, a higher filter weight of 0.7 was used to reduce the excessive noise, but this resulted in an increased image lag and loss in temporal resolution. However, for the pixels within the ROI, a lower filter weight of 0.2 was used, thus preserving temporal resolution. ${ }^{5,6}$ Under these conditions, the signal-to-noise ratios in uniform regions within the ROI and in the dose-reduced periphery were similar.

\section{D Printed Model Setup}

After receiving approval from our institutional review board at University at Buffalo (IRB 567513), we generated ten 3D printed aneurysm models (Objet Eden 260V PolyJet 3D printer; Stratasys, Eden Prairie, Minnesota) from 1 patient's 3D rotational intracranial DSA and CTA. Details of the additive printing process are found in earlier publications. ${ }^{7,8}$ A 21-mm-thick aluminum block was placed in the FOV to simulate the attenuation offered by the cranium. For a $70-$ to $76-\mathrm{kVp}$ input $\mathrm{x}$-ray spectrum, the beam quality reaching the detector with a $21-\mathrm{mm}$ aluminum block in the FOV is similar to the average beam quality with a head. ${ }^{16}$

All aneurysms underwent primary coiling, with each aneurysm treated with the same set of devices: 7F Shuttle-SL guide sheath (Cook Medical, Bloomington, Indiana), SL-10 microcatheter (Stryker Neurovascular, Kalamazoo, Michigan), 0.14-inch Synchro 14 microguidewire (Stryker Neurovascular), and 8 $\mathrm{mm} \times 20 \mathrm{~cm}$ Target 360 soft coils (Stryker Neurovascular). A $50 \%$ dilution of iohexol solution (Omnipaque 240; GE Healthcare, Piscataway, New Jersey) was used as the contrast agent for all DSA runs. These images were acquired at a research computer station using custom-built acquisition software.

\section{Image Analysis}

Subjective Assessment. Two experienced neurointerventionalists evaluated the images randomly displayed on the research station. Both were blinded to patient data and ROI status. These raters evaluated and scored the diagnostic quality of the regular DSA (ie, RDI) and DSA when the ROI was applied for dose reduction (ROI-DRI).

Each aneurysm was treated using both the ROI-DRI and the RDI protocols. For each aneurysm coiling intervention, a set of 4 images was generated at various stages of the intervention. Thus, each intervention generated 8 images (ie, 4 ROI-DRI images; Fig 1; and 4 RDI images; On-line Fig 2). 
Both RDI and ROI-DRI images were acquired at the following stages of the simulated intervention:

- Angiographic run preintervention: diagnostic DSA showing aneurysm and parent vessel morphology and associated proximal and distal vasculature (Fig $1 A$ ).

- Microwire navigation: roadmap image showing the microwire inside the aneurysm and leaving the tip of the guide catheter (Fig 1B).

- Microcatheter navigation: roadmap image showing the guide tip and microcatheter inside the aneurysm (Fig 1C).

- Postcoiling: roadmap image showing the coils inside the aneurysm and the guide catheter tip (Fig 1D).

For each defined stage, image quality was rated in 3 categories:

Unacceptable, when it was difficult

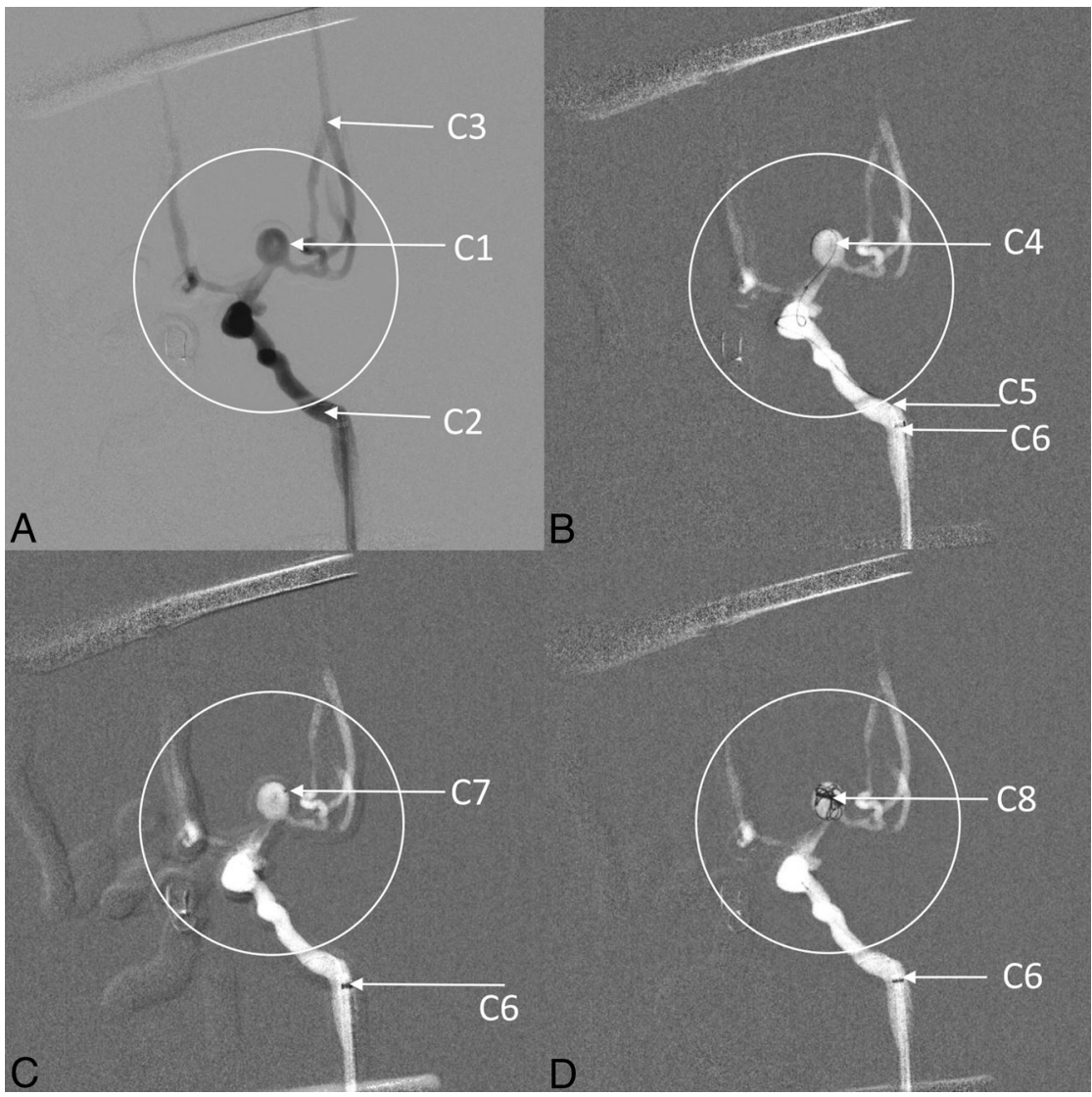

FIG 1. A, A single frame from an ROI-dose-reduced-intervention DSA run. Parent vessel morphology ( $C 1)$, proximal vessels (C2), and distal vessels (C3) are visible (arrows). The position of the $\mathrm{ROI}$ is indicated by the white circular boundary. $B$, A single frame of the ROI-DRI fluoroscopic roadmap. The microwire is seen leaving the guide catheter (C5) and inside the aneurysm (C4). The guide catheter tip is visible (C6). C, A single frame of the ROI-DRI fluoroscopic roadmap. The guide tip is seen (C6). The distal tip of the microcatheter is seen inside the aneurysm (C7). D, A single frame of the ROI-DRI fluoroscopic roadmap. The coil is visible inside the aneurysm (C8). The guide tip is visible (C6). In comparison with the RDI images shown in On-line Fig 2, the integral dose for each of these ROI-DRI images is $38 \%$ of the integral dose of the RDI images, thus achieving an integral dose reduction of $62 \%$.

Table 1: Image-quality ratings ${ }^{\text {a }}$

\begin{tabular}{|c|c|c|c|c|}
\hline $\begin{array}{c}\text { Timing of } \\
\text { Image Acquisition }\end{array}$ & Visibility of & $\begin{array}{c}\text { Scores } \\
\text { Unacceptable }\end{array}$ & $\begin{array}{c}\text { Scores } \\
\text { Acceptable }\end{array}$ & $\begin{array}{c}\text { Scores } \\
\text { High }\end{array}$ \\
\hline \multirow[t]{3}{*}{ Angiographic run preintervention } & 1) Aneurysm-parent vessel morphology (Cl) & 1 & 2 & 3 \\
\hline & 2) Proximal vessel (C2) & 1 & 2 & 3 \\
\hline & 3) Distal vessel (C3) & 1 & 2 & 3 \\
\hline \multirow[t]{3}{*}{ Microwire navigation } & 4) Microwire inside aneurysm (C4) & 1 & 2 & 3 \\
\hline & 5) Microwire leaving guide (C5) & 1 & 2 & 3 \\
\hline & 6) Guide tip (C6) & 1 & 2 & 3 \\
\hline \multirow[t]{2}{*}{ Microcatheter navigation } & 7) Distal tip of microcatheter in aneurysm (C7) & 1 & 2 & 3 \\
\hline & 8) Guide tip (C6) & 1 & 2 & 3 \\
\hline \multirow[t]{2}{*}{ Postcoiling } & 9) Coil inside aneurysm (C8) & 1 & 2 & 3 \\
\hline & 10) Guide tip (C6) & 1 & 2 & 3 \\
\hline
\end{tabular}

Note:- C indicates criterion.

${ }^{a}$ Used to evaluate the diagnostic quality of both standard cerebral angiograms and cerebral angiograms when the ROI was applied for $\mathrm{x}$-ray dose reduction.

\section{Statistical Analysis}

The Wilcoxon signed rank sum test was used to compare the scores from the neurointerventionalists' ratings of the RDI and ROI-DRI images. Intrarater 
Table 2: Summary statistics for scores of image quality with and without ROI-DRI application

\begin{tabular}{|c|c|c|c|c|c|c|c|c|c|c|c|c|c|}
\hline \multirow[b]{2}{*}{ Visibility of } & \multirow{2}{*}{$\begin{array}{l}\text { ROI-DRI } \\
\text { Applied }\end{array}$} & \multicolumn{3}{|c|}{$\begin{array}{c}\text { Rater } 1 \\
\text { Frequency } \\
\text { of Scores }^{\mathrm{a}}\end{array}$} & \multicolumn{3}{|c|}{$\begin{array}{c}\text { Rater } 2 \\
\text { Frequency } \\
\text { of Scores }^{\mathrm{a}}\end{array}$} & \multicolumn{3}{|c|}{ Rater 1} & \multicolumn{3}{|c|}{ Rater 2} \\
\hline & & 1 & 2 & 3 & 1 & 2 & 3 & Mean/Median & SD & $P$ Value & Mean/Median & SD & $P$ Value \\
\hline \multirow[t]{2}{*}{$(\mathrm{Cl})^{\mathrm{b}}$} & Yes & 0 & 14 & 6 & 0 & 16 & 4 & $2.30 / 2.0$ & 0.47 & .75 & $2.20 / 2$ & 0.41 & 1.00 \\
\hline & No & 2 & 8 & 10 & 0 & 16 & 4 & $2.40 / 2.5$ & 0.68 & & $2.20 / 2$ & 0.41 & \\
\hline \multirow[t]{2}{*}{$(\mathrm{C} 2)^{\mathrm{b}}$} & Yes & 1 & 9 & 10 & 0 & 15 & 5 & 2.45 & 0.60 & .77 & 2.25 & 0.44 & .62 \\
\hline & No & 1 & 7 & 12 & 0 & 17 & 3 & 2.55 & 0.60 & & 2.15 & 0.37 & \\
\hline \multirow[t]{2}{*}{$(\mathrm{C} 3)^{\mathrm{b}}$} & Yes & 1 & 13 & 6 & 1 & 16 & 3 & $2.25 / 2$ & 0.55 & 1.00 & 2.10 & 0.45 & 1.00 \\
\hline & No & 2 & 10 & 8 & 1 & 16 & 3 & $2.30 / 2$ & 0.66 & & 2.10 & 0.45 & \\
\hline \multirow[t]{2}{*}{$(\mathrm{C} 4)^{\mathrm{b}}$} & Yes & 1 & 7 & 12 & 0 & 13 & 7 & 2.55 & 0.60 & 1.00 & 2.35 & 0.49 & .12 \\
\hline & No & 2 & 6 & 12 & 0 & 17 & 3 & 2.50 & 0.69 & & 2.15 & 0.37 & \\
\hline \multirow[t]{2}{*}{$(C 5)^{b}$} & Yes & 1 & 14 & 5 & 0 & 16 & 4 & $2.20 / 2$ & 0.52 & .53 & $2.20 / 2$ & 0.41 & .62 \\
\hline & No & 1 & 17 & 2 & 2 & 17 & 1 & $2.05 / 2$ & 0.39 & & $1.95 / 2$ & 0.39 & \\
\hline \multirow[t]{2}{*}{$(\mathrm{C} 6)^{\mathrm{c}}$} & Yes & 16 & 35 & 9 & 15 & 40 & 5 & $1.88 / 2$ & 0.64 & .09 & $1.83 / 2$ & 0.56 & .47 \\
\hline & No & 6 & 46 & 8 & 12 & 43 & 5 & $2.03 / 2$ & 0.49 & & $1.88 / 2$ & 0.52 & \\
\hline \multirow[t]{2}{*}{$(\mathrm{C} 7)^{\mathrm{b}}$} & Yes & 2 & 13 & 5 & 0 & 17 & 3 & $2.15 / 2$ & 0.59 & 1.00 & $2.15 / 2$ & 0.37 & .37 \\
\hline & No & 3 & 12 & 5 & 2 & 16 & 2 & $2.10 / 2$ & 0.64 & & $2.00 / 2$ & 0.46 & \\
\hline \multirow[t]{2}{*}{$(\mathrm{C} 8)^{\mathrm{b}}$} & Yes & 0 & 7 & 13 & 0 & 10 & 10 & $2.65 / 3$ & 0.49 & .62 & $2.50 / 2.5$ & 0.51 & .5 \\
\hline & No & 0 & 5 & 15 & 0 & 12 & 8 & $2.75 / 3$ & 0.44 & & $2.40 / 2.5$ & 0.50 & \\
\hline
\end{tabular}

amage-quality scores: 1 = unacceptable, 2 = acceptable, $3=$ high quality.

${ }^{b}$ A total of 10 aneurysms were treated. Each treated aneurysm (ROI-DRI or standard) had $1 \mathrm{Cl} / \mathrm{C} 2 / \mathrm{C} 3 / \mathrm{C} 4 / \mathrm{C} 5 / \mathrm{C} 7 / \mathrm{C} 8 \mathrm{criterion}$ to rate and $3 \mathrm{C} 6 \mathrm{criteria}$ (because it appears thrice on the basis of the treatment stage, Table 1). Thus, $10 \mathrm{Cl} / \mathrm{C} 2 / \mathrm{C} 3 / \mathrm{C} 4 / \mathrm{C} 5 / \mathrm{C} 7 \mathrm{C} 8$ criteria were rated by each rater for 10 aneurysms that were treated by either the standard or ROI-DRI approach. Because each image was shown twice to a rater, it resulted in the rating of $20 \mathrm{Cl} / \mathrm{C} 2 / \mathrm{C} 3 / \mathrm{C} 4 / \mathrm{C} 5 / \mathrm{C} 7 / \mathrm{C} 8 \mathrm{criteria}$ each in the ROI-DRI and standard images.

' The $\mathrm{C} 6$ count is 60 because the $\mathrm{C} 6$ criterion appears thrice on the basis of the treatment stage.

agreement was measured by Kendall $\tau$-b correlation coefficient, which is a nonparametric measure of association based on the number of concordances and discordances in paired observations. The paired variables were considered correlated if the correlation coefficient was close to 1 and uncorrelated if the correlation coefficient was close to zero. Interrater agreement was measured by $\kappa$ statistics. Assessment of the degree of agreement was based on $\kappa$ values $(<0=$ poor, $0.01-0.20=$ slight, $0.21-$ $0.40=$ fair, $0.41-0.60=$ moderate, $0.61-0.80=$ substantial, $0.81-0.99=$ almost perfect). Because each image was rated twice by the same reviewer, bootstrap resampling was used to calculate the $\kappa$ statistics.

\section{RESULTS}

In this study, the $K_{\mathrm{ROI}}$ was measured as an average of $0.45 \mathrm{mGy}$ per frame, and the $K_{\text {Periphery }}$ was measured as an average of 0.11 mGy per frame. The ROI area was $18 \%$ of the total FOV. The total kerma-area product with and without the dose-reduction technique was calculated as 25.44 and $66.89 \mathrm{mGy} \times \mathrm{cm}^{2}$, respectively. Using these values, we calculated the kerma-area product ratio with and without the dose-reduction technique to be $38 \%$. Therefore, the integral dose per frame with the ROI attenuator was 38\% of the integral dose per frame without the ROI attenuator, thus achieving an integral dose reduction of $62 \%$ per image. The air kerma in the periphery with the ROI-DRI was $20 \%$ of that in side the ROI.

The mean scores for ratings of the ROI-DRI images and RDI images were compared. None of the criteria scores were statistically different (Table 2). Visibility of the guide catheter tip was evaluated on images obtained during microwire navigation, microcatheter navigation, and postcoiling, for a total of 120 rating responses. However, no significant difference was seen (rater 1, $P=.095$; rater $2, P=.47$ ) for ROI-DRI images versus RDI images.

\section{Intrarater Agreement}

Tables 3 and 4 show the frequency, percentage, and Kendall $\tau$ correlation coefficients of agreement for each rater. For visibility of the tip of the guide catheter, substantial agreement was seen in rater 1's intrarater assessment of the ROI-DRI $(P<.001$, Kendall $\tau=0.716)$ and the RDI $(P<.001$, Kendall $\tau=0.699)$, whereas agreement was moderate (ROI-DRI, Kendall $\tau=0.569$ ) to fair (RDI, Kendall $\tau=0.398$ ) in rater 2's assessment. For each criterion in which visibility outside the ROI (ie, periphery) was assessed (proximal vessel, distal vessel, microwire leaving the guide catheter, and guide catheter tip), intrarater agreement ranged from moderate to perfect (Tables 3 and 4 ). The overall intrarater agreement for raters 1 and 2 was substantial (Kendall $\tau=0.62887$, $P$ value $<.001)$. For ROI images, the Kendall $\tau$ was 0.63171 with $P<.001$; and for images without ROIs, the Kendall $\tau$ was 0.62789 with $P<.001$ (Tables 3 and 4 ).

\section{Interrater Agreement}

The $\kappa$ characteristic ranged from -0.0345 (for visibility of the aneurysm and parent vessel morphology) to 0.7 (for visibility of the coil inside the aneurysm) (Table 5). More than 50\% agreement was achieved in all criteria ratings for ROI-DRI intervention cases. In cases of RDI intervention, $>50 \%$ agreement was seen in $75 \%$ of the ratings.

The overall interrater agreement for all criteria was fair $(\kappa=$ $0.2816 ; 95 \%$ CI, $0.2060-0.3571)$. In an analysis of the cohorts separately, the $\kappa$ value was 0.2832 (95\% CI, 0.1697-0.3967) in the ROIDRI cohort and 0.2358 (95\% CI, 0.1345-0.3371) in the RDI cohort.

\section{DISCUSSION}

Dose reduction in $\mathrm{X}$-ray image-guided interventions is of paramount concern. ROI fluoroscopy, a dose-reduction technique us- 
Table 3: Intrarater agreement relative to image-quality assessment with the Kendall $\tau$ correlation coefficients

\begin{tabular}{|c|c|c|c|c|c|c|c|}
\hline \multirow[b]{2}{*}{ Visibility of } & \multirow{2}{*}{$\begin{array}{l}\text { ROI-DRI } \\
\text { Applied }\end{array}$} & \multirow{2}{*}{$\begin{array}{l}\text { Rater } 1 \\
\text { (f) (\%) }\end{array}$} & \multirow{2}{*}{$\begin{array}{c}\text { Rater } 2 \\
\text { (f) (\%) }\end{array}$} & \multicolumn{2}{|c|}{ Rater 1} & \multicolumn{2}{|c|}{ Rater 2} \\
\hline & & & & Kendall $\tau$ & $P$ Value & Kendall $\boldsymbol{\tau}$ & $P$ Value \\
\hline \multirow[t]{2}{*}{$\mathrm{Cl}$} & Yes & $8(80)$ & $10(100)$ & 0.52381 & .12 & 1.00000 & $.0027^{a}$ \\
\hline & No & $10(100)$ & $8(80)$ & 1.00000 & $.001^{\mathrm{a}}$ & 0.37500 & .2606 \\
\hline \multirow[t]{2}{*}{ C2 } & Yes & $7(70)$ & $7(70)$ & 0.59423 & .06 & 0.40825 & .2207 \\
\hline & No & $5(50)$ & $9(90)$ & 0.32418 & .31 & 0.66667 & $.0455^{a}$ \\
\hline \multirow[t]{2}{*}{$\mathrm{C} 3$} & Yes & $7(70)$ & $8(80)$ & 0.59588 & .06 & 0.54571 & .0935 \\
\hline & No & $10(100)$ & $8(80)$ & 1.00000 & $.001^{\mathrm{a}}$ & 0.54571 & .0935 \\
\hline \multirow[t]{2}{*}{ C4 } & Yes & $7(70)$ & $5(50)$ & 0.58926 & .06 & 0.27217 & .4142 \\
\hline & No & $6(60)$ & $9(90)$ & 0.61721 & .05 & 0.66667 & $.0455^{\mathrm{a}}$ \\
\hline \multirow[t]{2}{*}{ C5 } & Yes & $9(90)$ & $10(100)$ & 0.31851 & .32 & 1.00000 & $.0027^{a}$ \\
\hline & No & $9(90)$ & $7(70)$ & 0.72761 & $.02^{\mathrm{a}}$ & 0.16667 & .6171 \\
\hline \multirow[t]{2}{*}{ C6 } & Yes & $26(86.7)$ & $20(66.7)$ & 0.71659 & $<.001^{\mathrm{a}}$ & 0.56984 & $.0012^{a}$ \\
\hline & No & $26(86.7)$ & $15(50)$ & 0.69942 & $<.001^{\mathrm{a}}$ & 0.39829 & $.0295^{a}$ \\
\hline \multirow[t]{2}{*}{$\mathrm{C7}$} & Yes & $9(90)$ & $7(70)$ & 0.84270 & $.007^{\mathrm{a}}$ & -0.16667 & .6171 \\
\hline & No & $8(80)$ & $8(80)$ & 0.76376 & $.01^{\mathrm{a}}$ & 0.62554 & .0528 \\
\hline \multirow[t]{2}{*}{ C8 } & Yes & $9(90)$ & $8(80)$ & 0.80178 & $.01^{\mathrm{a}}$ & 0.66667 & $.0455^{\mathrm{a}}$ \\
\hline & No & $7(70)$ & $8(80)$ & 0.21822 & .51 & 0.65465 & $.0495^{\mathrm{a}}$ \\
\hline
\end{tabular}

Note:- f indicates frequency.

a Significant.

Table 4: Overall Kendall $\tau$ correlation coefficients

\begin{tabular}{lcclcc}
\hline & Kendall $\boldsymbol{\tau}$ & $\boldsymbol{P}$ Value & & Kendall $\boldsymbol{\tau}$ & $\boldsymbol{P}$ Value \\
\hline Rater 1 & 0.70822 & $<.001^{\mathrm{a}}$ & With ROI & 0.69476 & $<.001^{\mathrm{a}}$ \\
& & & Without ROI & 0.73072 & $<.000^{\mathrm{a}}$ \\
Rater 2 & 0.49899 & $<.001^{\mathrm{a}}$ & With ROI & 0.55057 & $<.000^{\mathrm{a}}$ \\
& & & Without ROI & 0.45918 & $<.001^{\mathrm{a}}$ \\
Pooled & \multirow{2}{*}{0.62887} & $<.001^{\mathrm{a}}$ & With ROI & 0.63171 & $<.001^{\mathrm{a}}$ \\
& & & Without ROI & 0.62789 & $<.001^{\mathrm{a}}$ \\
\hline
\end{tabular}

${ }^{a}$ Significant.

Table 5: Interrater agreement relative to image-quality assessment with $\tau$ statistics with bootstrap resampling

\begin{tabular}{lcccccc} 
Visibility of & $\begin{array}{c}\text { ROI-DRI } \\
\text { Applied }\end{array}$ & Frequency & Percentage & $\boldsymbol{\kappa}$ & $\begin{array}{r}95 \% \mathrm{Cl} \\
\text { (Lower) }\end{array}$ & $\begin{array}{r}95 \% \mathrm{Cl} \\
\text { (Upper) }\end{array}$ \\
\hline C1 & Yes & 16 & 80 & 0.4737 & 0.0438 & 0.9036 \\
& No & 8 & 40 & -0.0345 & -0.3341 & 0.2651 \\
C2 & Yes & 12 & 60 & 0.2558 & -0.0765 & 0.5881 \\
& No & 14 & 70 & 0.2040 & 0.2212 & 0.2620 \\
C3 & Yes & 12 & 60 & 0.0751 & -0.2676 & 0.4179 \\
& No & 11 & 55 & 0.1589 & -0.1344 & 0.4521 \\
C4 & Yes & 10 & 50 & 0.1111 & -0.2336 & 0.4559 \\
& No & 9 & 45 & 0.1603 & -0.0227 & 0.3433 \\
C5 & Yes & 17 & 85 & 0.6154 & 0.2684 & 0.9623 \\
& No & 16 & 80 & 0.2523 & -0.2669 & 0.7715 \\
C6 & Yes & 31 & 51.67 & 0.0914 & -0.1349 & 0.3177 \\
& No & 39 & 65 & 0.1656 & -0.0773 & 0.4084 \\
C7 & Yes & 10 & 50 & -0.2195 & -0.4131 & -0.0259 \\
& No & 12 & 60 & 0.1667 & -0.1959 & 0.5293 \\
C8 & Yes & 17 & 85 & 0.7000 & 0.4014 & 0.9986 \\
& No & 13 & 65 & 0.3636 & 0.0705 & 0.6568 \\
\hline
\end{tabular}

by Robert et al $^{18}$ involving a dose-reduction technique that used an attenuator with a thin central region and a gradually increasing thickness away from the center. With this type of attenuator, only the lower spatial frequency components in the image were modulated, and brightness in the image was equalized using a high-pass spatial digital filter.

Work on variable ROI shapes was conducted by Xu et al. ${ }^{19}$ They developed an ROI attenuator device made of a $16 \times$ 16 piston array driven by stepper motors that could generate patient-specific ROIs to reduce the $\mathrm{x}$-ray dose during interventions.

A $100 \%$ dose reduction in the periphery can be achieved by collimating the FOV to the ROI. In such cases, realtime imaging of the periphery is lost. During neuroendovascular interventions, visibility of the periphery is necessary. Moreover, the neurointerventionalist needs to see the position of the guide tip in the FOV. Loss of the guide catheter with difficult access can change the outcome of an intervention and add ing an $\mathrm{x}$-ray beam-modulating ROI attenuator, was first presented in earlier work $^{1}$; the use of this attenuator was subsequently demonstrated in an anthropomorphic phantom. ${ }^{2}$ Image brightness was equalized by subtracting a preacquired mask of the attenuator. A similar concept to the ROI attenuator is the $\mathrm{x}$-ray fovea introduced by Labbe et $\mathrm{al},{ }^{17}$ which is a device that uses a semitransparent collimator with an open circular hole to reduce the dose. In that study, the authors compensated for image brightness by scaling the pixel intensity value according to the ratio of the attenuation coefficients of the attenuator in the ROI and the periphery. Comparable with these concepts was the work to the risk of complications. Similarly, visibility of the distal circulation is equally important.

None of the above-mentioned techniques included noise reduction in the peripheral regions to improve image quality. A whole-image noise-reduction technique was proposed for $\mathrm{x}$-ray images using a combination of temporal filtering and spatial filtering techniques based on object detection and motion. ${ }^{20}$ In places where no motion was present, temporal filtering was favored, whereas a spatial blurring filter was used when motion was encountered.

In our study, a spatially different recursive temporal filtering 
scheme was applied to reduce the noise in the image. A higher filter weight was used in the periphery because the noise is excessive due to less quanta reaching the detector, whereas the weight within the ROI is lower because the regular dose is reaching the detector.

Reducing the incident primary exposure to the patient in the periphery regions results in the reduction of patient skin and organ dose within the periphery region. Furthermore, reducing the primary exposure in the periphery results in reduced backscatter and thus reduced dose to the skin in the ROI. The dose reduction achieved using this technique is dependent on the size of the ROI opening and the thickness and material of the ROI attenuator. A greater reduction in dose can be achieved using either a thicker material or a smaller ROI area or both.

\section{Intra- and Interrater Agreement}

The subjective assessment of 2 comparable radiographic techniques by image-quality rating scores is standard practice. This has been used for image assessment following the application of a metal artifact-reduction algorithm. ${ }^{21-23}$ We used intrarater agreement, interrater agreement, and comparison of mean scores. Our hypothesis was that the use of ROI-DRI would not deteriorate image quality and would not adversely affect the clinical utility of the sequence. In our study, we found that there was no significant difference (Table 2 ) in the scores assigned by each rater and between the 2 raters (because every image was shown twice).

When intrarater agreement was analyzed, visibility of the guide catheter tip had the highest agreement, with significance achieved in scores assigned by both raters and in the cohorts of ROI-DRI and RDI alone. The highest agreement could be attributed to the large size of the guide catheter compared with the sizes of the microcatheters, microwire, and coils. However, this indicates that quality was not lost when the ROI was applied to standard images. Similarly, when the ROI field was analyzed, the highest agreement was seen in the visibility of the coil mass. Intrarater agreement was significant, except when the ROI was not applied (rater 1, Tables 3 and 4). This increased agreement could be due to the large size of the coil mass compared with other devices. Overall intrarater agreement was significant $(P<.001)$ (rater 1: ROI-DRI, Kendall $\tau=0.69476$; RDI, Kendall $\tau=0.73072$; rater 2: ROI-DRI, Kendall $\tau=0.55057$; RDI, Kendall $\tau=0.45918$ ).

The overall interrater agreement in our study was fair. However, when the ROI was applied, substantial significance $(\kappa=$ 0.6154 and 0.7 ) was attained for the criteria of microwire emerging out of the guide catheter tip and coil visibility. Better agreement between the raters in the analysis of the ROI field may be because of a reduction in scatter radiation due to the reduction of primary radiation in the periphery.

This study demonstrated a (simulated) neurointervention in a reduced-dose environment using the technique of dose reduction with a clear, real-time view of the periphery. We implemented a simple approach by replacing an existing compensation filter in the $\mathrm{x}$-ray tube with a single ROI attenuator with a fixed ROI area. With this setup, we had 2 dose-reduction options available in the $\mathrm{x}$-ray unit that are controlled independently by the operator/interventionist: a set of conventional $100 \%$ dose-reducing lead col- limators and the ROI attenuator. The dose-reduction system can be integrated into other existing $\mathrm{x}$-ray machines using this implementation.

The geometric magnification was kept the same for all interventions so that all comparisons were equivalent. Increasing the distance between the patient and the detector would increase the magnification and geometric unsharpness; however, the use of the ROI attenuator would not affect these image characteristics. There would be some reduction of scatter with a larger air gap resulting from increased distance between the patient and the detector, but this effect would be minimal with the ROI attenuator because the reduced size of the region of higher intensity will already have reduced scatter and improved the contrast-to-noise ratio. If the magnification were increased by increasing the source-to-image receptor distance, the exposure parameters would have to be increased to maintain the same detector exposure (hence signal to noise ratio) whether the ROI attenuator was used or not.

During neurointervention, most of the fluoroscopic time is spent on the interventional part of the procedure. The use of this novel technology is expected to reduce the total dose because during our simulations, once the aneurysm was located, the ROI attenuator was moved into the FOV and centered on the aneurysm. Then the intervention was performed, including guidance, placement, and deployment of treatment devices. In the future, neurointervention can be performed using ROI-DRI without compromising the quality of the imaging.

\section{Study Limitations}

In this study, the exposure parameters for a particular aneurysm geometry were determined by the automatic exposure control while using the RDI protocol, and the same settings were manually maintained while using the ROI-DRI protocol. In earlier $\mathrm{x}$ ray imaging systems with image intensifiers, the automatic exposure control signal was derived from light sensed over a central region of variable, selectable size. For stable exposure parameter tracking, the ROI attenuator would be constrained to the center of the FOV and to being larger than the sensed area. With digital flat panel detector systems, only the unattenuated region of the image with the ROI attenuator could be used to calculate automatic exposure control parameters, thus minimizing the potential for erroneous brightness selection or unstable automatic exposurecontrol searching behavior. With proper design, the location of this sensed area could be made to track with movement of the ROI attenuator to off the central axis locations.

In our current setup, the dose reduction for the average technique parameters was measured separately using an ionization chamber placed in the FOV. A real-time skin-dose tracking system for neurointerventional procedures was developed and is currently being used in a clinical setting to map skin doses during these procedures. ${ }^{24}$ Currently, work is in progress to integrate the use of the ROI attenuator with this system. ${ }^{25}$ This will allow us to measure the dose reduction achieved using our above-mentioned technique in real-time during a clinical procedure.

Ours is the initial step in the development of this technology. Neurointervention is fast evolving with newer devices. To maintain uniformity, we tested primary coiling in the current study. The visibility of stents and flow diverters needs to be further tested.

AJNR Am J Neuroradiol 39:734-41 Apr 2018 www.ajnr.org 


\section{CONCLUSIONS}

Our study has shown that significant dose reduction (62\%) with a live peripheral image can be achieved without compromising feature visibility at the ROI and periphery during neuroendovascular interventions.

Disclosures: Ciprian N. Ionita—RELATED: Grant: Toshiba Medical Systems, Comments: research grant; UNRELATED: Employment: University at Buffalo, Comments: Assistant Professor in the Biomedical Engineering Department; Grants/Grants Pending: National Institutes of Health, Medtronic, Toshiba America Medical Systems, New York State, Comments: research grants; Payment for Lectures Including Service on Speakers Bureaus: Toshiba Medical Systems. Kenneth V. Snyder-UNRELATED: Payment for Lectures Including Service on Speakers Bureaus: Toshiba Medical Systems and Jacobs Institute. L. Nelson Hopkins-UNRELATED: Board Membership: Claret Medical; Consultancy: Boston Scientific, Abbott, Cordis, Medtronic; Employment: University at Buffalo Neurosurgery, Jacobs Institute, Kaleida Health; Payment for Lectures Including Service on Speakers Bureaus: Memorial Healthcare System, Complete Conference Management; Stock/Stock Options: Boston Scientific, Claret Medical, Augmenix, Endomation, Silk Road Medical, Ostial, Apama Medical, StimSox, Photolitec, ValenTx, Axtria, Ocular Therapeutix, The Stroke Project, Comments: financial interests, no money received. Daniel $\mathrm{R}$. Bednarek-UNRELATED: Grants/Grants Pending: Toshiba Medical Systems*; Patents (Planned, Pending or Issued): Toshiba Medical Systems, Comments: Joint patents have been issued but no money has been paid to the institution or self, though it may be in the future; Royalties: Toshiba Medical Systems, Comments: Royalties were paid to the institution and self for dose-tracking system technology license*. Stephen Rudin—RELATED: Grant: Toshiba Medical Systems, Comments: for equipment support*; UNRELATED: Grants/Grants Pending: National Institutes of Health, Comments: R01EB002873*; Patents (Planned, Pending or Issued): Toshiba Medical Systems, Comments: joint patent authorship; no money was involved; Royalties: Toshiba Medical Systems.* Adnan H. Siddiqui-UNRELATED: Board Membership: Intersocietal Accreditation Commission; Consultancy: Codman \& Shurtleff, Medtronic, GuidePoint Global Consulting, Penumbra, Stryker Neurovascular, MicroVention, W.L. Gore \& Associates, Three Rivers Medical, Corindus, Amnis Therapeutics, CereVasc, Pulsar Vascular, The Stroke Project, Cerebrotech Medical Systems, Rapid Medical, Neuravi, Silk Road Medical, Rebound Therapeutics; Stock/ Stock Options: StimMed, Valor Medical, NeuroTechnology Investors, Cardinal Health, Medina Medical Systems, Buffalo Technology Partners, International Medical Distribution Partners, Endostream Medical; Other: National Steering Committees: Penumbra, Separator 3D trial, Covidien (now Medtronic), SWIFT PRIME and SWIFT DIRECT trials, MicroVention, FRED trial, MicroVention, CONFIDENCE study, LARGE trial, POSITIVE trial, Penumbra, COMPASS trial, INVEST trial. Elad I. Levy — UNRELATED: Board Membership: American Spinal Injury Association Impairment Scale Clinical Advisory Board for Stryker Neurovascular, Advisory Board of NeXtGen Biologics, Advisory Board of MEDX, and Advisory Board for Cognition Medical Corp, Comments: no money paid to me; Consultancy: Pulsar Vascular; Employment: University at Buffalo Neurosurgery and the University at Buffalo, State University of New York, Comments: render medical/legal opinion as an expert witness, no money paid to me; all money received goes to charitable donations; Payment for Lectures Including Service on Speakers Bureaus: Covidien/Medtronic; Stock/Stock Options: Intratech Medical, NeXtGen Biologics, Neuravi/Codman Neuro, Comments: Neuravi, which is now Codman Neuro (Johnson \& Johnson) was sold in April 2017; Other: Abbott Vascular, Comments: carotid training sessions for physicians. *Money paid to the institution.

\section{ACKNOWLEDGMENTS}

The authors thank Paul H. Dressel, BFA, for preparation of the illustrations, Tingting Zhuang, MA, for statistical analysis, and Debra J. Zimmer for editorial assistance.

\section{REFERENCES}

1. Rudin S, Bednarek DR. Region of interest fluoroscopy. Med Phys 1992;19:1183-89 CrossRef Medline

2. Rudin S, Bednarek DR, Kezerashvili M, et al. Clinical application of region-of-interest techniques to radiologic imaging. Radiographics 1996;16:895-902 CrossRef Medline

3. Rudin S, Guterman LR, Granger WE, et al. Application of region-ofinterest imaging techniques to neurointerventional radiology. $R a-$ diology 1996;199:870-73 CrossRef Medline

4. Panse AS, Swetadri Vasan SN, Jain A, et al. Dose reduction by moving a region of interest (ROI) beam attenuator to follow a moving ob- ject of interest. Proc SPIE Int Soc Opt Eng 2012;8313:831355 CrossRef Medline

5. Swetadri Vasan SN, Ionita C, Bednarek DR, et al. A novel region of interest (ROI) imaging technique for biplane imaging in interventional suites: high-resolution small field-of-view imaging in the frontal plane and dose-reduced, large field-of-view standard-resolution imaging in the lateral plane. Proc SPIE Int Soc Opt Eng 2014; 9033:90332F CrossRef Medline

6. Vasan SN, Pope L, Ionita CN, et al. Dose reduction in fluoroscopic interventions using a combination of a region of interest (ROI) $x$ ray attenuator and spatially-different, temporally-variable temporal filtering. Proc SPIE Int Soc Opt Eng 2013;8668:86683Y CrossRef Medline

7. Ionita CN, Mokin M, Varble N, et al. Challenges and limitations of patient-specific vascular phantom fabrication using 3D PolyJet printing. Proc SPIE Int Soc Opt Eng 2014;9038:90380M CrossRef Medline

8. Russ M, O'Hara R, Setlur Nagesh SV, et al. Treatment planning for image-guided neuro-vascular interventions using patient-specific 3D printed phantoms. Proc SPIE Int Soc Opt Eng 2015;9417. pii: 941726 CrossRef Medline

9. Ionita CN, Garcia VL, Bednarek DR, et al. Effect of injection technique on temporal parametric imaging derived from digital subtraction angiography in patient specific phantoms. Proc SPIE Int Soc Opt Eng 2014;9038:90380L CrossRef Medline

10. Mokin M, Ionita CN, Nagesh SV, et al. Primary stentriever versus combined stentriever plus aspiration thrombectomy approaches: in vitro stroke model comparison. J Neurointerv Surg 2015;7:453-57 CrossRef Medline

11. Mokin M, Setlur Nagesh SV, Ionita CN, et al. Comparison of modern stroke thrombectomy approaches using an in vitro cerebrovascular occlusion model. AJNR Am J Neuroradiol 2015;36:547-51 CrossRef Medline

12. Mokin M, Setlur Nagesh SV, Ionita CN, et al. Stent retriever thrombectomy with the Cover accessory device versus proximal protection with a balloon guide catheter: in vitro stroke model comparison. J Neurointerv Surg 2016;8:413-17 CrossRef Medline

13. Massoumzadeh P, Rudin S, Bednarek DR. Filter material selection for region of interest radiologic imaging. Med Phys 1998;25:161-71 CrossRef Medline

14. Setlur Nagesh S, Jain A, Ionita C, et al. SU-D-134-03; design considerations for a dose-reducing region of interest (ROI) attenuator built in the collimator assembly of a fluoroscopic interventional C-arm. Med Phys 2013;40:112 CrossRef

15. Kotre CJ, Guibelalde E. Optimization of variable temporal averaging in digital fluoroscopy. Br J Radiol 2004;77:675-78 CrossRef Medline

16. International Electrotechnical Commission. IEC 62220-1-1:2015. Medical electrical equipment - Characteristics of digital x-ray imaging devices Part 1-1: Determination of the detective quantum efficiency - detectors used in radiographic imaging. https://webstore.iec.ch/publication/ 21937. Accessed November 16, 2017

17. Labbe MS, Chiu MY, Rzeszotarski MS, et al. The x-ray fovea, a device for reducing x-ray dose in fluoroscopy. Med Phys 1994;21:471-81 CrossRef Medline

18. Robert N, Komljenovic PT, Rowlands JA. A filtering method for signal equalization in region-of-interest fluoroscopy. Med Phys 2002; 29:736-47 CrossRef Medline

19. Xu T, Le HQ, Molloi S. Patient-specific region-of-interest fluoroscopy device for X-ray dose reduction. Radiology 2003;226:585-92 CrossRef Medline

20. Aufrichtig R, Wilson DL. X-ray fluoroscopy spatio-temporal filtering with object detection. IEEE Trans Med Imaging 1995;14:733-46 CrossRef Medline

21. Buhk JH, Groth M, Sehner S, et al. Application of a novel metal artifact correction algorithm in flat-panel CT after coil embolization of brain aneurysms: intraindividual comparison. Rofo 2013; 185:824-29 CrossRef Medline 
22. Hung SC, Wu CC, Lin CJ, et al. Artifact reduction of different metallic implants in flat detector C-arm CT. AJNR Am J Neuroradiol 2014;35:1288-92 CrossRef Medline

23. van der Bom IM, Hou SY, Puri AS, et al. Reduction of coil mass artifacts in high-resolution flat detector conebeam CT of cerebral stent-assisted coiling. AJNR Am J Neuroradiol 2013;34:2163-70 CrossRef Medline

24. Rana VK, Rudin S, Bednarek DR. A tracking system to calculate patient skin dose in real-time during neurointerventional procedures using a biplane x-ray imaging system. Med Phys 2016;43:5131 CrossRef Medline

25. Vijayan S, Xiong Z, Rudin S, et al. Calculation of the entrance skin dose distribution for fluoroscopically guided interventions using a pencil beam backscatter model. J Med Imaging (Bellingham) 2017;4: 031203 CrossRef Medline 